\title{
Expression of a Surface-Associated Antigen on Y-Cells in the Cat Lateral Geniculate Nucleus Is Regulated by Visual Experience
}

\author{
Mriganka Sur, ${ }^{1}$ Douglas O. Frost, ${ }^{2}$ and Susan Hockfield ${ }^{2}$ \\ 'Department of Brain and Cognitive Sciences, Massachusetts Institute of Technology, Cambridge, Massachusetts 02139, \\ and 'Section of Neuroanatomy, Yale University School of Medicine, New Haven, Connecticut 06510
}

The monoclonal antibody Cat-301, generated against cat spinal cord (McKay and Hockfield, 1982), recognizes a surface-associated antigen that, in the cat lateral geniculate nucleus (LGN), is selectively expressed on Y-cells (Hockfield et al., 1983; Hendry et al., 1984; Sur et al., 1984). We now report that the antigen recognized by Cat-301 appears late in development, along a time course similar to that described for the maturation of the physiological properties of $Y$-cells in the LGN, and that its expression is sharply reduced by monocular lid suture or dark-rearing from birth, 2 visual deprivation procedures that lead to a reduction in the proportion of Y-cells recorded physiologically in the LGN (Sherman et al., 1972; Kratz et al., 1979; reviewed in Sherman and Spear, 1982). Monocular lid suture in the adult has no effect on Cat-301 antigen levels or, as previously reported (Sherman et al., 1972), on the proportion of physiologically recorded Y-cells. In addition, reversing the monocular deprivation in adulthood by opening the neonatally sutured eye and suturing closed the previously normal eye for 6 months restores neither normal levels of Cat-301 labeling nor, as previously reported (Geisert et al., 1982), the proportion of recordable Y-cells. The development of Cat-301 immunoreactivity thus parallels the development of LGN Y-cell physiology. The relative reduction in levels of immunoreactivity consequent to neonatal, but not adult, visual deprivation shows that Cat-301 antigen expression does not simply reflect the level of visually evoked electrical activity in the LGN, but rather reflects a process that depends on the nature of visual experience early in life. This stands in contrast to previous reports of reduction in cytochrome oxidase staining following visual deprivation even in adult animals (WongRiley and Riley, 1983), and to reports of other activity-related changes in biochemical features of cells in the LGN. Our results suggest that the expression of an antigen on a specific class of neurons in the cat LGN, Y-cells, is mediated by visual experience from birth. Visual deprivation, known

\footnotetext{
Received Mar. 9, 1987; revised Aug. 10, 1987; accepted Aug. 26, 1987

We thank Martha MacAvoy, Preston Garraghty, Mary Kritzer, and Elizabeth Waldvogel for their assistance. We also thank Dr. Ronald McKay for his contributions to the study and for many helpful discussions. Supported by USPHS Grant EY07023 and the Whitaker Fund (M.S.), EY03465 and March of Dimes Grant 5-417 (D.O.F.), and EY0651 1 and NS18040 (S.H.). M.S. is an A. P. Sloan Kesearch Fellow. S.H. is a Klingenstein Fellow in Neuroscience.

Correspondence should be addressed to Mriganka Sur, Department of Brain and Cognitive Sciences, M.I.T., E25-618, Cambridge, MA 02139.

Copyright (c) 1988 Society for Neuroscience $0270-6474 / 88 / 030874-09 \$ 02.00 / 0$
}

to cause anatomical and physiological changes at the level of single neurons in the LGN, also produces molecular changes in specific neuronal classes.

The cat's visual pathway, from retina through the lateral geniculatc nuclcus (LGN) to visual cortex, is comprised of at least 2 parallel streams, the $\mathrm{X}$ - and $\mathrm{Y}$-cell systems (see, for recent reviews, Rodieck, 1979; Lennie, 1980; Sherman and Spear, 1982). In the retina, $\mathrm{Y}$-cells can be distinguished from X-cells by physiological properties and anatomical features (Enroth-Cugell and Robson, 1966; Saito, 1983; Fukuda et al., 1984; Stanford and Sherman, 1984). In the LGN, X- and Y-cells relay the physiological properties of their retinal afferents to the visual cortex (Hoffman et al., 1972). Morphologically, most Y-cells in the LGN have large somata and thick dendrites that project radially and frequently cross laminar borders (Friedlander et al., 1981). Such morphological features have been described as class 1 features (Guillery, 1966). In contrast, X-cells have mediumsized somata with thinner dendrites that are oriented largely normal to the laminar borders of the LGN (Friedlander et al., 1981).

Monoclonal antibody Cat-301, generated against homogenized cat spinal cord (McKay and Hockfield, 1982), recognizes a surface-associated antigen on subsets of neurons in many parts of the mammalian central nervous system (Hockfield et al., 1983). Biochemical studies (S. Zaremba and S. Hockfield, unpublished observations) suggest that the antigen recognized by Cat-301 is a proteoglycan. One group of neurons recognized by Cat-301 lies in the cat LGN (Hockfield et al., 1983; Hendry et al., 1984; Sur et al., 1984). Here, Cat-301 stains cells in laminae $\mathrm{A}, \mathrm{A} 1$, and $\mathrm{C}$, in interlaminar zones, in the medial interlaminar nucleus, and in the perigeniculate nucleus. Several lines of evidence, including a comparison of soma sizes, morphology, and cortical projection patterns of cells labeled with Cat-301, indicate that the antibody identifies Y-cells in the LGN (Sur et al., 1984). Briefly, Cat-301 labels cells in the LGN that are similar in size to a population of physiologically identified $\mathrm{Y}$-cells labeled intracellularly with HRP and that are larger than intracellularly labeled populations of either X- or W-cells (Friedlander et al., 1981; Stanford et al., 1983). Morphologically, Cat301-labeled cells in the A- and C-laminae all have class 1 features; such features distinguish Y-cells in the LGN (Friedlander et al., 1981; cf. Weller and Humphrey, 1985). Cortical area 18 is a target of $Y$-cells in the A laminae (Stone and Dreher, 1973; Harvey, 1980; Humphrey ct al., 1985) and of Y- and W-cells in the C laminae (Raczkowski and Rosenquist, 1980; 
Table 1. Counts of Cat-301-labeled neurons in the LGN of normal, dark-reared, monocularly sutured, reverse-sutured, and adult monocularly sutured cats that were examined in detail for this study

\begin{tabular}{|c|c|c|c|c|}
\hline \multirow[b]{2}{*}{ Condition } & \multicolumn{2}{|l|}{ Cat 1} & \multicolumn{2}{|l|}{ Cat 2} \\
\hline & $\begin{array}{l}\text { Lamina } \\
\text { A }\end{array}$ & $\begin{array}{l}\text { Lamina } \\
\text { Al }\end{array}$ & $\begin{array}{l}\text { Lamina } \\
\text { A }\end{array}$ & $\begin{array}{l}\text { Lamina } \\
\text { Al }\end{array}$ \\
\hline Normal & 259 & 357 & 247 & 333 \\
\hline Dark-reared & $51^{*}$ & $97^{*}$ & $67^{*}$ & $85^{*}$ \\
\hline \multicolumn{5}{|l|}{ Monocularly lid-sutured } \\
\hline Ipsi eye (lamina A1) deprived & 296 & $97^{*}$ & 273 & $104 *$ \\
\hline Contra eye (lamina A) deprived & $64 *$ & 330 & $59^{*}$ & 364 \\
\hline \multicolumn{5}{|l|}{ Reverse suture } \\
\hline Ipsi eye (lamina A1) deprived first & 281 & $101^{*}$ & & \\
\hline Contra eye (lamina A) deprived first & $88^{*}$ & 321 & & \\
\hline Adult onset monocular suture & 288 & 346 & & \\
\hline
\end{tabular}

Each entry represents the total number of Cat-301-positive neurons counted in 6 fields of view, each $0.283 \mathrm{~mm}^{2}$ (total area $=1.7 \mathrm{~mm}^{2}$ ). Two sections near the center of the rostral-caudal extent of the LGN were counted in each cat. In each section, 3 fields in the binocular regions of the laminae of interest were sampled, and the numbers of cells counted in the 6 fields through a given lamina were summed. In normal and dark-reared cats, the A and Al laminae on the same side of the brain were counted; in monocularly sutured and reverse-sutured cats, laminae A and Al on both sides of the brain were counted, while in the adult-sutured cat, the laminae A and AI counted were both ipsilateral to the deprived eye.

$* p<0.001$ compared to normal counts (Mann-Whitney $U$ test).

Humphrey et al., 1985). Injection of HRP into area 18, followed by immunohistochemical staining of the LGN with Cat-301, indicates that neurons in the $\mathrm{A}$ laminae that project to area 18 are also all antibody-positive. In the $\mathrm{C}$ laminae, large neurons (Y-cells) filled retrogradely with HRP from area 18 injections are antibody-positive, but small retrogradely labeled neurons (W-cells) are not (M. Sur and S. Hockfield, unpublished observations).

In the present study, we sought to determine whether, during normal and abnormal development, there is a correlation between the physiological expression of $Y$-cell properties and the expression of the Cat-301 antigen in the cat LGN. We have followed the postnatal development of Cat-301 immunoreactivity in the normal cat LGN, and examined Cat-301 antigen expression in adult cats following 2 abnormal rearing paradigms (monocular lid suture and dark-rearing), both of which lead to a reduction in the proportion of $\mathrm{Y}$-cells recorded physiologically in the LGN (see, for review, Sherman and Spear, 1982). We found that Cat-301 staining is severely depleted in visually deprived LGN laminae following each of these rearing conditions. In control experiments in which the proportion of $\mathrm{Y}$-cells recorded in the adult LGN is not altered, Cat-301 immunoreactivity in the LGN is also not altered. Thus, the development of Cat-301 immunoreactivity seems to reflect the development of $Y$-cell properties and not simply levels of visually evoked, electrical neuronal activity in the LGN. Some of these data have been reported previously in abstracts (Hockfield et al., 1985; MacAvoy et al., 1986).

\section{Materials and Methods}

Subjects. Experiments were performed on 12 adult cats and 7 kittens. Of the adult cats, 4 were normal. Four cats were raised with monocular lid suture from birth to 1 year or more. After a year, one of the monocularly sutured cats had the sutured eye opened and the open eye sutured (reverse suture) for 6 months before it was killed; the other monocularly sutured cats remained sutured until they were killed. Three cats were reared in the dark from birth to 4-6 months. One normally reared adult cat had one eye sutured for 6 months before death. Of the kittens, one was killed on the day of birth, one at $30 \mathrm{~d}, 2$ at $60 \mathrm{~d}$, one at $90 \mathrm{~d}$, and 2 at $180 \mathrm{~d}$ after birth. Animals were anesthetized deeply with sodium pentobarbital and perfused transcardially with phosphatebuffered saline followed by $4 \%$ paraformaldehyde.

Histochemical procedures. Sucrose-infiltrated brains were frozen and cut coronally at $50 \mu \mathrm{m}$. From each brain, a set of sections through the LGN was processed, free-floating, for immunohistochemistry (McKay and Hockfield, 1982). Sections were incubated in monoclonal antibody Cat-301 (as full-strength supernatant) with $2 \%$ Triton X-100 overnight, rinsed in phosphate-buffered saline, and then incubated in HRP-conjugated secondary antibody (Cappel) diluted 1:100 in tissue culture medium (Dulbecco's modified Eagle's medium with $10 \%$ fetal calf serum) with $2 \%$ Triton X-100 for $2 \mathrm{hr}$. Sections were than reacted with 3,3'diaminobenzidine (with cobalt intensification; Adams, 1977) for visualization of HRP. All procedures in all cats were identical.

Data analysis. Apart from comparing visually the number of Cat301 -stained cells and the intensity of staining following various rearing procedures or at different ages, we counted the number of stained neurons in the A laminae of the LGN (these counts were used for Table 1, and Figs. 2 and 4). Representative sections were counterstained with cresyl violet. In each kitten, we counted Cat-301-stained cells with welldefined nucleoli in individual fields of view under a $20 \times$ objective. Three fields of view were chosen in the binocular segment of lamina A, and 3 in lamina A1, medially, centrally, and laterally in each of 2 sections near the center of the rostral-caudal extent of one LGN in each kitten. The 12 counts for each kitten at each age were summed and expressed as a percentage of the mean number of Cat-301-stained neurons counted using the same procedure in 2 adult cats ( $>1$ ycar old). Since the LGN grows in volume between birth and about 8 weeks postnatally (Kalil, 1978), this procedure samples larger fractions of the LGN in younger kittens than in older animals. Thus, we slightly overestimate the number of Cat-301-positive neurons in the younger animals as compared to that in animals 8 weeks of age and older.

In 2 monocularly sutured and 2 dark-reared cats (as well as in 2 normal adult cats for comparison), we counted cells in the LGN as a function of eccentricity in the visual field, since the effects of monocular lid suture on the proportions of recorded $Y$-cells are observed only in the binocular segment, while the effects of dark-rearing on recorded Y-cells are observed in both monocular and binocular segments of the LGN (Sherman et al., 1972; Kratz et al., 1979). In each cat, 3 coronal sections through the central part of the LGN were selected. In each section, Cat-301-stained cells with well-defined nucleoli were counted under a $20 \times$ objective in 4 fields of view from medial to lateral in the LGN. The 4 locations in lamina A were judged from Sanderson's (1971) maps to correspond to visual-field eccentricities of $0^{\circ}-5^{\circ}, 5^{\circ}-15^{\circ}, 15^{\circ}$ $45^{\circ}$, and $45^{\circ}-90^{\circ}$, respectively. Lamina $A 1$, representing the binocular 


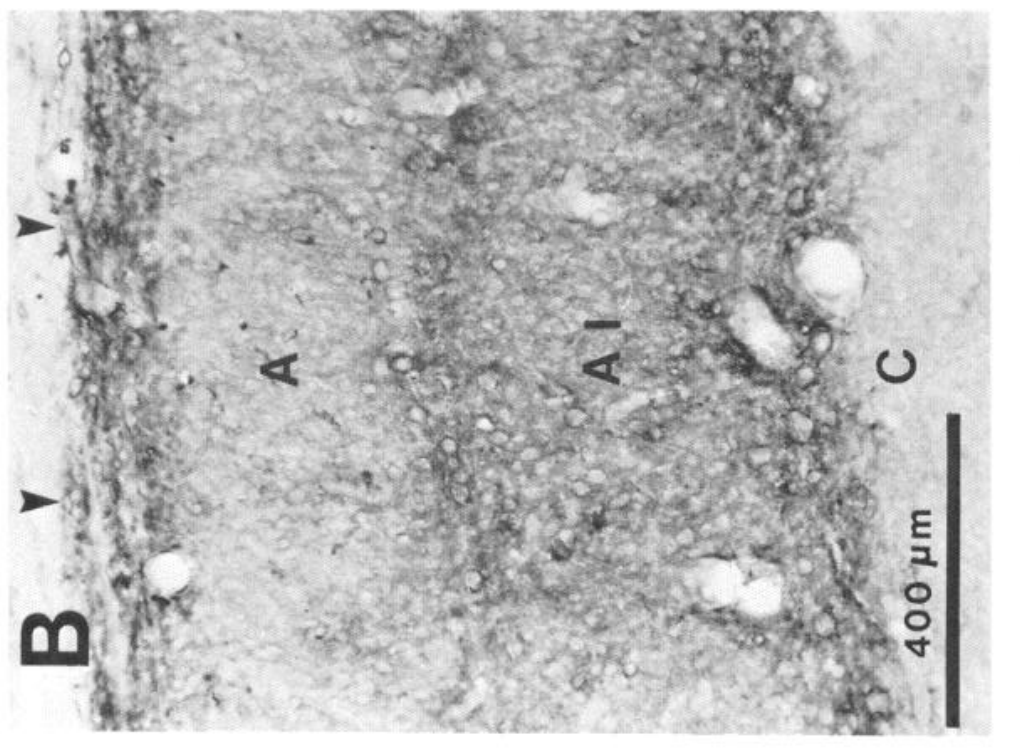

窇

ن.

ํํํํํำ

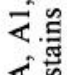

范

疍.

.

离这

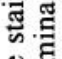

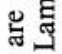

妾宅

خิำ

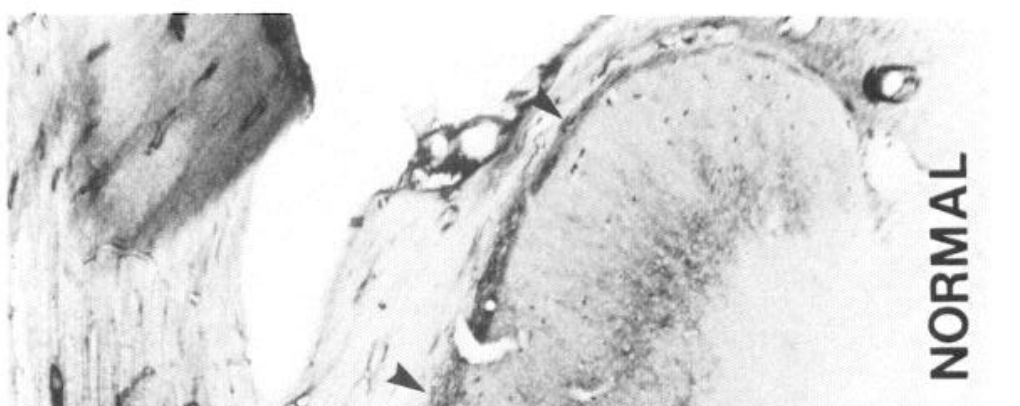

ㅎำ

$\Xi \frac{1}{2}$

ठำ 봄

तั

돈.

동 웅

i)
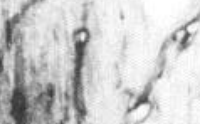

Vlim $x$.
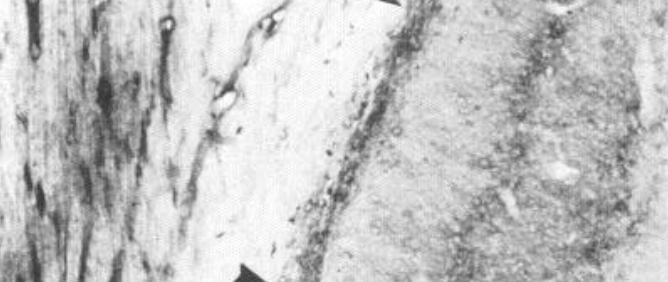

4 s.
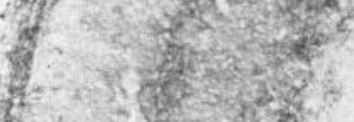

$4<<0$
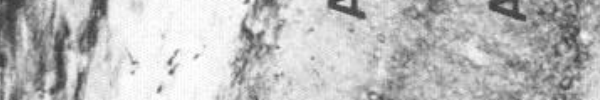

13
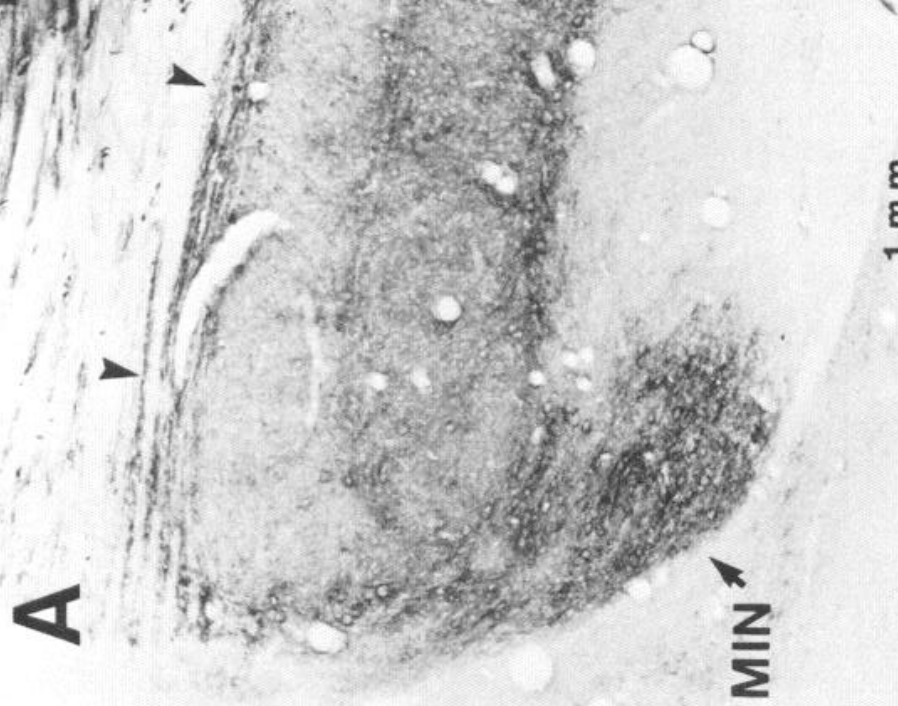


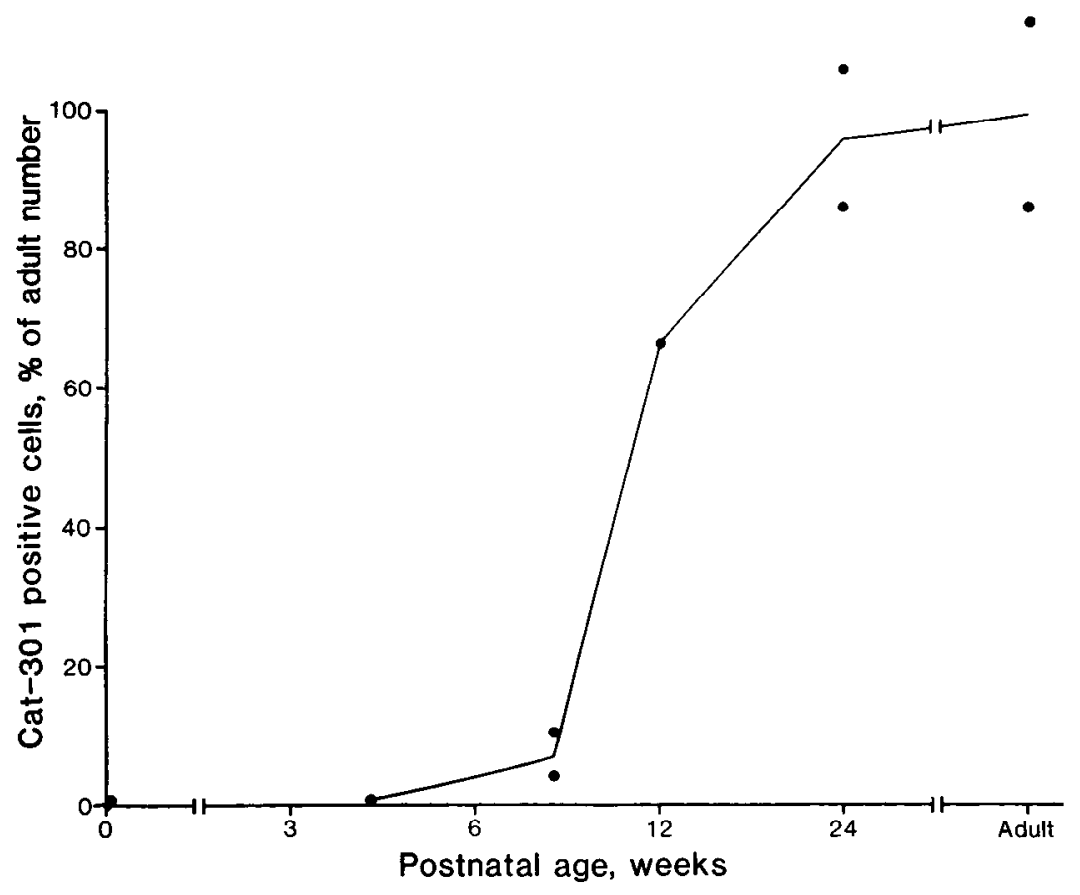

Figure 2. Development of Cat-301positive neurons in the binocular region of the A laminae of the LGN. Cat-301stained cells in representative sections through the $L G N$ were counted in each kitten at the ages shown, and are graphed here as a percentage of the number of labclcd cells in adult cats (see Materials and Methods for details). Counts are from one cat each on days 0,30 , and 90 , and from 2 cats on days 60 and 180 . Two normal adult cats were used for comparison. Each point represents a single animal, and the line connects the mean values at each age. visual field through the ipsilateral eye, contained only the first 3 eccentricity bins. In normal and dark-reared cats, the counts in laminae A and $A 1$ were made in the same LGN. In the monocularly sutured cats and in the reverse-sutured cats, counts were made in the A and Al laminae on both sides of the brain. In the adult sutured cat, counts were made in lamina A and in lamina Al ipsilateral to the sutured eye. The counts in the binocular segment are summarized in Table 1.

\section{Results}

\section{Normal adult cats}

Figure 1 shows Cat-301 staining in the LGN of a normal adult cat. Labeled cells lie in laminae A, Al, and the dorsal C laminae, in interlaminar zones, and in the medial interlaminar nucleus. The perigeniculate nucleus that lies dorsal to the LGN also stains intensely. Staining in lamina A1 is consistently greater than in lamina $A$. The pattern of Cat-301 staining in normal adult cats confirms earlier reports of Cat-301 labeling in the cat LGN (Hockfield et al., 1983; Hendry et al., 1984). The antigen is localized in the regions of the somata and proximal dendrites, either on the cell surface or in the closely apposed extracellular space (Hockfield and McKay, 1983; Hockfield et al., 1983; S. Zarcm ba and S. Hockfield, unpublished observations). We have described elsewhere the evidence that Cat-301-stained cells in the LGN are Y-cells (see above).

\section{Development of Cat-301 expression}

At birth, neurons in the kitten LGN do not exhibit the characteristic surface-associated Cat-301 staining (Fig. 2). By 8 weeks after birth, a few neurons are Cat-301-positive (Fig. 2). The intensity of staining and number of antibody-positive cells increase rapidly thereafter to reach adult levels between 90 and $180 \mathrm{~d}$ postnatally (Fig. 2).

Recordings from LGN cells during development suggest that the physiological properties of Y-cells mature later than those of X-cells (Daniels et al., 1978). While some cells can be classified physiologically as $\mathrm{Y}$-cells as early as 4 weeks, the adult proportions of $Y$-cells are recorded only by 12-16 weeks post- natally (Mangel et al., 1983). The development of Cat-301 staining in the LGN thus generally parallels the physiological maturation of Y-cell properties in the LGN. The following experiments suggest that the expression of the Cat-301 antigen may be significantly related to the physiological development of Y-cell properties in the LGN. At the same time, the expression of the antigen is not simply tied to features in the development of Y-cells related to soma size, since cell size is essentially adultlike by the eighth postnatal week (Kalil, 1978).

\section{Cat-301 staining in visually deprived cats}

The relatively late expression of the antigen recognized by Cat301 suggested to us that its expression in the LGN might be related to visual experience. The development of the physiological properties of Y-cells in the LGN is particularly susceptible to postnatal visual deprivation (see, for review, Movshon and Van Sluyters, 1981; Sherman and Spear, 1982). Specifically, monocular deprivation by lid suture from the time of normal eye opening to adulthood and binocular deprivation by darkrearing from birth to adulthood both lead to a severe reduction in the proportions of Y-cells recorded physiologically in deprived laminae in the LGN (Sherman et al., 1972; Hoffman and Cynader, 1977; Kratz et al., 1979; Mower et al., 1981; Geisert et al., 1982; Kratz, 1982). One difference between the effects of monocular lid suture and dark-rearing is that in monocularly sutured cats $\mathrm{Y}$-cells are reduced in the binocular segment of deprived lamina A but not in the monocular segment, while in dark-reared cats $\mathrm{Y}$-cells are reduced in both monocular and binocular segments of lamina $\mathrm{A}$. The underlying reason for this difference may stem from both binocularly competitive as well as noncompetitive mechanisms controlling Y-cell development (Sherman and Spear, 1982).

Cat-301 staining in monocularly lid-sutured cats is severely depleted in deprived laminae, but is normal in nondeprived laminae (Fig. 3, $A, B, E$ ). Counts of labeled neurons as a function of eccentricity in the visual-field representation indicate that Cat-301-labeled cells are less numerous in the binocular segment 

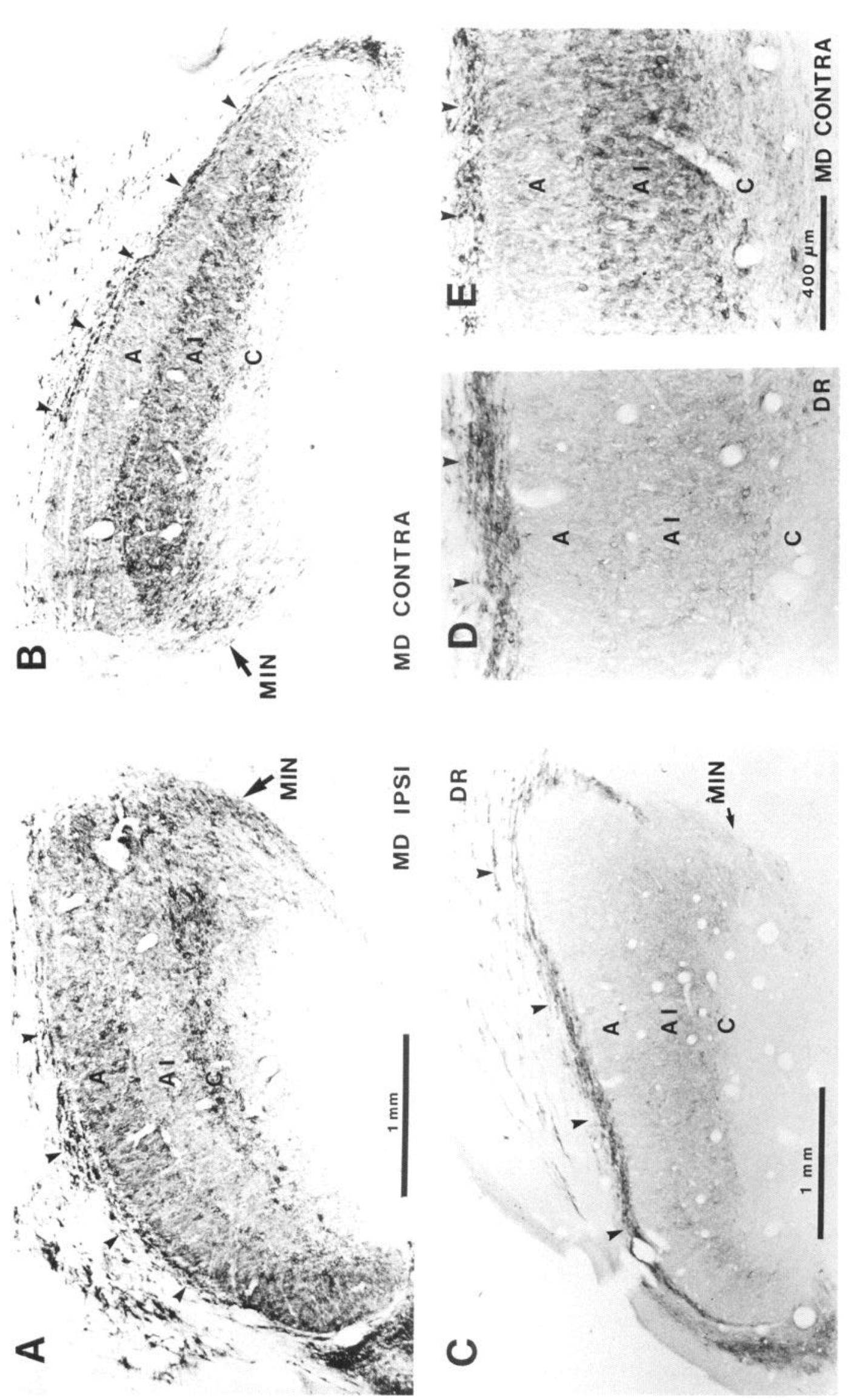

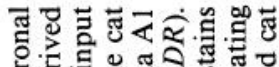

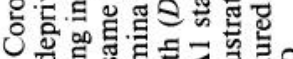

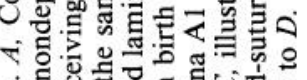

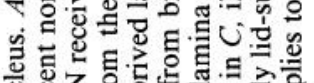

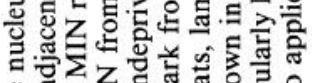

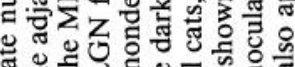

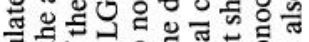

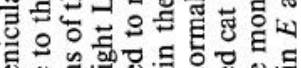

总

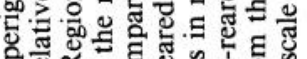

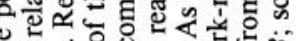

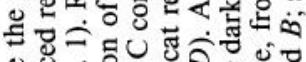

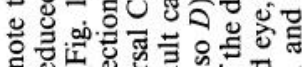
过

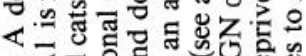

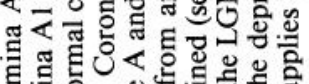

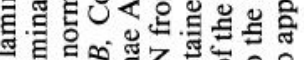

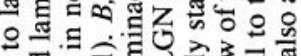

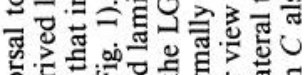

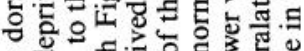

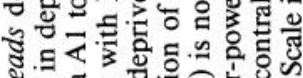

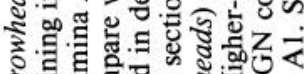

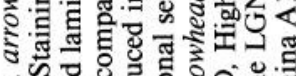
की

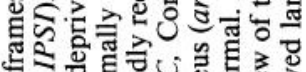

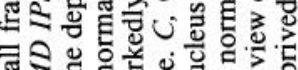

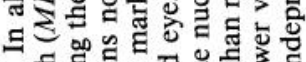

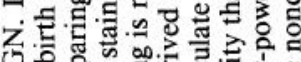

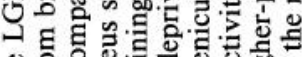

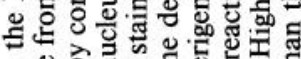

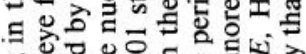

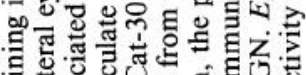

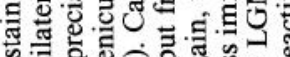

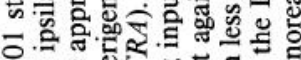
원

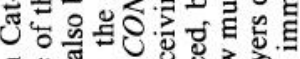
5

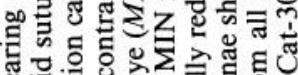

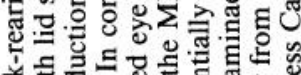

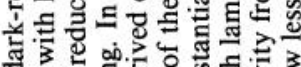

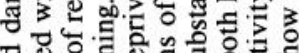

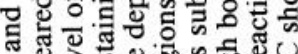

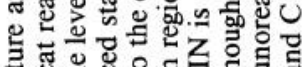

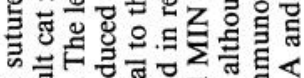

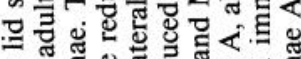
惢

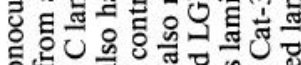

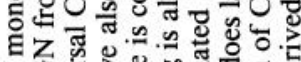

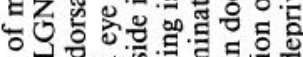

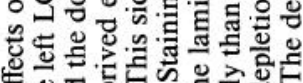

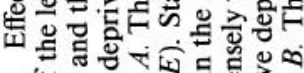

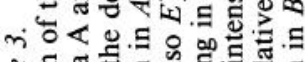

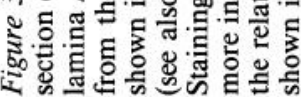




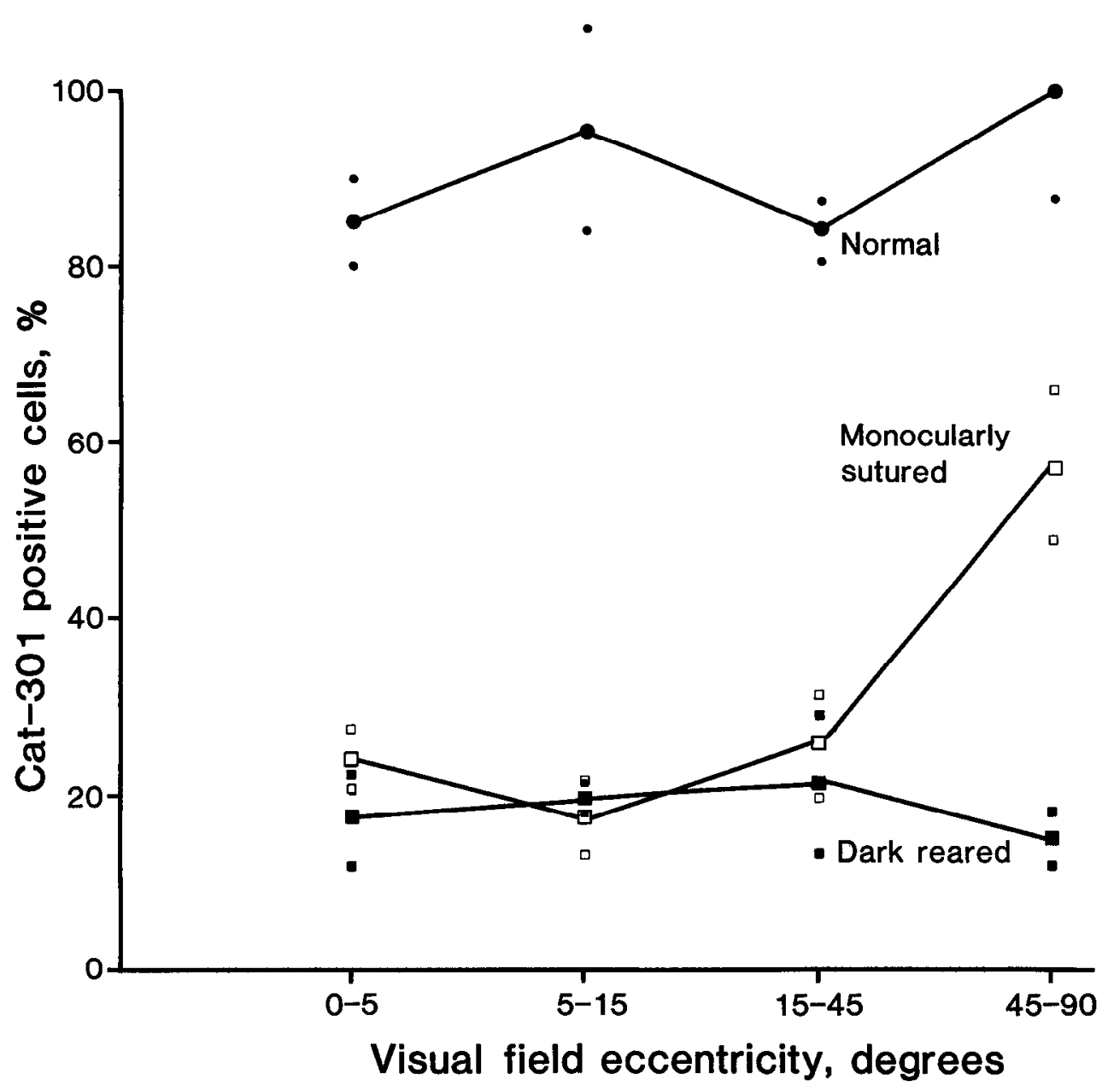

Figure 4. Number of Cat-301-positive cells in the A laminae of the LGN as a function of visual-field eccentricity in normal, monocularly sutured, and dark-reared adult cats. The raw counts were obtained from 3 sections in each of 2 cats from each category, as described in Materials and Methods. Each point on the graph at the first 3 eccentricities (binocular visual-field representation) represents the sum of the number of labeled cells counted in the 3 fields through lamina $A$ and the 3 fields through lamina $\mathrm{Al}$ at that eccentricity. For the $45^{\circ}-90^{\circ}$ eccentricity (monocular visual field), each point represents twice the number of labeled cells counted in the 3 fields through lamina $A$ at that eccentricity. In the normal and dark-reared cats, the $A$ and A1 laminae counted are on the same side of the brain; in the monocularly reared cat, they are on opposite sides of the brain and innervated by the deprived eye. All the sums were averaged for the 2 cats in each category and expressed as a percentage of the maximum cell count in any eccentricity bin (which was the $45^{\circ}-90^{\circ}$ bin in normal adult cats). Each point represented by a small symbol represents cells in the appropriate bin from one cat. The lines connect the means for each bin, represented by large symbols. of the LGN (including lamina $\mathrm{A} 1$ and the binocular portion of lamina $\mathrm{A}$ ), but that the monocular segment contains more labeled neurons (Fig. 4). In dark-reared cats, the number of Cat301-labeled neurons is drastically reduced throughout the nucleus (Fig. 3, $C, D$ ), including binocular and monocular segments of the A laminae (Fig. 4). Although staining is much reduced compared to normal, lamina $\mathrm{Al}$ in dark-reared cats stains more intensely than lamina $\mathrm{A}$ (Fig. 3, $C, D$ ), just as it does in normal adult cats (Fig. 1). Finally, despite the depletion in Cat-301 staining in deprived laminae following monocular lid suture or dark-rearing, the perigeniculate nucleus still stains as dark as normal (compare Figs. 1, 3) and thus serves as an internal control for the effects of visual deprivation on the laminated LGN.

In addition to laminae $A, A 1$, and $C$ of the $L G N$, the medial interlaminar nucleus also contains a large population of physiologically identified Y-cells (Kratz et al., 1978a; Dreher and Sefton, 1979) and a large number of Cat-301-positive neurons (Fig. 1). As in the LGN, visual deprivation reduces the proportion of Y-cells recorded in the nucleus (Kratz et al., 1978b). Monocular lid suture substantially reduces the number of Cat301 -positive neurons in deprived regions of the medial interlaminar nucleus (Fig. 3, $A, B$ ), and dark-rearing nearly abolishes Cat-301 staining there (Fig. $3 C$ ).

\section{Control experiments}

Recent studies have shown that the histochemical visualization of some enzymes can be altered by visual deprivation in adult animals (Wong-Riley and Riley, 1983; Wong-Riley and Carroll, 1984). These enzymatic changes are thought to reflect changes in the level of neuronal activity. In order to determine whether the loss of Cat-301 immunoreactivity reflects such a change in activity or changes specifically related to developmental processes, we examined one cat monocularly lid-sutured for 6 months as an adult. Such cats show no reduction in the proportions of $Y$-cells recorded in deprived laminae (Sherman et al., 1972), and here we found no loss of Cat-301 staining in deprived LGN laminae (Table 1). The pattern and intensity of staining in the deprived and nondeprived LGN laminac of the cat monocularly lid-sutured as an adult are indistinguishable from Cat-301 staining in normal cats (Fig. 1).

Other experiments in visually deprived adult cats also suggest that the expression of Cat-301 in the LGN reflects developmental processes and not simply the level of neuronal activity. When, in adult animals reared with monocular suture from birth, the sutured eye is opened and the originally open eye is sutured closed (reverse suture), there is no recovery of Y-cells 
in the originally deprived LGN layers, nor do the originally normal LGN layers lose their complement of Y-cells (Geisert et al., 1982). Here, the cat that was neonatally lid-sutured for 1 year and then reverse-sutured for 6 months did not recover Cat301 staining in the LGN laminae innervated by the initially deprived eye (Table 1). The layers innervated by the eye that was open from birth and later sutured showed normal levels of Cat-301 staining (Tablc 1). The pattern and intensity of Cat301 staining in the reverse-sutured cat are thus indistinguishable from those in monocularly sutured cats prior to reverse suture (Fig. 3, $A, B$ ).

\section{Discussion}

\section{Development and plasticity of Cat-301 staining}

Monoclonal antibody Cal-301 recognizes a surface-associated antigen on Y-cells in the cat LGN. The antigen is expressed late in development, and its expression is suppressed by neonatal, but not adult, visual deprivation. These 2 facts suggest that the expression of the Cat-301 antigen is regulated by visual experience during an early critical period and not simply by the level of visually evoked neuronal spike activity in the LGN. Importantly, the changes we report in levels of Cat-301 immunoreactivity correlate highly with previously reported changes in the physiologically assessed $Y$-cell composition of the LGN, both during normal development and following several different kinds of early visual deprivation.

The development of Cat-301 staining in normal kittens is consistent with the notion that the antigen recognized by the antibody is expressed on physiologically mature Y-cells. Reduction in Cat-301 staining following visual deprivation might then imply that many Y-cells in deprived LGN laminae had failed to reach physiological maturity. Our experiments cannot address the physiological fate of Y-cells in deprived LGN laminae. Experiments by Friedlander et al. (1982) correlating the structure of physiologically identified LGN neurons with their function indicate that many neurons in deprived LGN laminae that would normally receive $Y$-cell input instead accept and retain $\mathrm{X}$-cell input or have abnormal input. We would expect that such neurons in deprived laminae would not be stained with Cat-301.

Monocular lid suture or dark-rearing does not cause a complete absence of Cat-301 staining in deprived laminae in the LGN; about $20-30 \%$ of cells remain stained in these laminae (Table 1 and Fig. 4). We interpret such cells as $Y$-cells that remain unaffected by monocular suture or dark-rearing, analogous to the population that can be recorded electrophysiologically following visual deprivation (Sherman et al., 1972; Kratz et al., 1979). Another possibility, not exclusive of the one above, is that all cells that normally express the Cat-301 antigen show reduced expression following visual deprivation, and the cells that we identify as remaining are simply the ones that maintain the highest levels of expression. Indeed, it is possible that there are gradations as well in the physiological effects of visual deprivation on LGN cells. This possibility, of course, does not alter the conclusion that both $\mathrm{Y}$-cells and the antigen identified by Cat-301 are affected by visual deprivation.

The Cat-301 antigen is expressed by many cell groups in the CNS, including motor neurons in the spinal cord ventral horn (Hockfield and McKay, 1983). The motoneurons lose Cat-301 immunoreactivity following neonatal lesions that disrupt their normal pattern of activity (R. Kolb and S. Hockfield, unpublished observations). The same lesions in adult animals have no effect on Cat-301 immunoreactivity. These findings further support the possibility that the Cat-301 antigen provides a marker for aspects of neuronal development. In the cat LGN, these aspects depend on visual experience, while in other structures they may depend on other factors.

\section{Comparison with other studies}

The experience-dependent expression of the Cat-301 antigen stands in marked contrast to other activity-dependent changes in the LGN, as well as to biochemical features of LGN cells that remain apparently unchanged following early visual deprivation. Monocular lid suture, monocular enucleation, and intravitreal tetrodotoxin injections in adult animals reduce cytochrome oxidase and pseudocholinesterase reactivity in deprived or deafferented laminae in the LGN (Wong-Riley, 1979; Graybiel and Ragsdale, 1982; Wong-Riley and Riley, 1983; Wong-Riley and Carroll, 1984). These histochemical studies show that enzyme levels decrease in deprived laminae of the LGN following deprivation even in adults, and suggest that, unlike enzyme levels, Cat-301 immunoreactivity is not simply tied to metabolic or neuronal spike activity.

In contrast to the reduction in Cat-301 immunoreactivity following neonatal visual deprivation, other biochemical features in the LGN remain apparently unchanged. The level of glutamic acid decarboxylase immunoreactivity does not change in the LGN following neonatal monocular lid suture (Bear et al., 1985), and the level of muscimol binding to GABA receptors in LGN cells is not altered following neonatal dark-rearing (Mower et al., 1985). The state of phosphorylation of microtubule-associated proteins (MAPs) is also normal in the LGN of monocularly deprived cats, even while deprivation-associated changes in MAPs are seen in the cortex (Aoki and Siekevitz, 1985). Thus, the reduced expression of the Cat-301 antigen that occurs as a consequence of early visual deprivation is a specific effect and is not due to a generalized disturbance of LGN metabolic activity.

Monocular lid suture results in a decrease in soma size in deprived laminae (Wiesel and Hubel, 1963; Guillery and Stelzner, 1970) but dark-rearing does not (Kratz et al., 1979). Cat301 staining is reduced in the LGN following both kinds of deprivation, providing further evidence that soma size by itself is not a critical variable in the expression of the antigen identified by Cat-301.

\section{Cat-301 may be a positive marker for $Y$-cell development}

While numerous reports have described changes in the physiology and anatomy of cells in the LGN during normal development and following visual deprivation, the mechanisms of these changes are poorly understood. Plasticity in the LGN Y-cell population likely involves both retrograde effects of binocular interactions in cortex (Movshon and Van Sluyters, 1981; Sherman and Spear, 1982), as well as anterograde effects of interactions between retinogeniculate $\mathrm{X}$ - and $\mathrm{Y}$-cell axons from the same eye during development (Sur et al., 1982; Garraghty et al., 1986). The changes we find in levels of the Cat-301 antigen may have similar underlying causes.

The correlation between the expression of the Cat-301 antigen and the physiological recording of Y-cells in the LGN suggests that the antigen may be important for the development or the maintenance of the response properties of these neurons. The evidence for associating Cat-301 labeling with $\mathrm{Y}$-cells in the LGN of normal adult cats (see the introduction), together with 
the results on normal development and visual deprivation presented here, strongly suggest that in normal animals Cat-301 provides a positive marker for the $Y$-cell population in the LGN. In visually deprived animals, Cat-301 labeling may distinguish normal from functionally altered neurons. Since previous studies of visual development and deprivation have relied on relatively time-intensive electrophysiological or anatomical assays of single neurons, a reagent that can distinguish betwecn normal and developmentally altered neurons could be of value.

The changes we describe in the antigen recognized by the monoclonal antibody Cat-301 demonstrate an experience-dependent alteration in the expression of a molecular species that characterizes a functional class of neuron. Whether the Cat-301 antigen represents an unusual molecular species or one member of a larger group of experience-dependent molecules remains to be determined. Experience-dependent changes in mRNA complexity (Grouse et al., 1979) and the state of phosphorylation of MAPs (Aoki and Siekevitz, 1985) in the visual cortex of darkreared cats have been reported. Together, these results suggest that normal visual experience is necessary for the expression of particular classes of molecules in the CNS. The ability of present technology to identify and characterize such molecules opens up the possibility that a molecular biology of experience-dependent neuronal development may now be accessible to study.

\section{References}

Adams, J. C. (1977) Technical considerations on the use of horseradish peroxidase as a neuronal marker. Neuroscience $2: 141-145$.

Aoki, C., and P. Siekevitz (1985) Ontogenetic changes in the cyclic adenosine $3^{\prime}, 5^{\prime}$-monophosphate stimulatable phosphorylation of cat visual cortex proteins, particulary of microtubule-associated protein 2 (MAP 2): Effects of normal and dark rearing and of the exposure to light. J. Neurosci. 5: 2465-2483.

Bear, M. F., D. E. Schmechel, and F. F. Ebner (1985) Glutamic acid decarboxylase in the striate cortex of normal and monocularly deprived kittens. J. Neurosci. 5: 1262-1275.

Daniels, J. D., J. D. Pettigrew, and J. L. Norman (1978) Development of single-neuron responses in kitten's lateral geniculate nucleus. J. Neurophysiol. 41: 1373-1393.

Dreher, B., and A. Sefton (1979) Properties of neurones in cat's dorsal lateral geniculate nucleus: A comparison between medial interlaminar and laminated parts of the nucleus. J. Comp. Neurol. 183: 47-64.

Enroth-Cugell, C., and J. G. Robson (1966) The contrast sensitivity of retinal ganglion cells of the cat. J. Physiol. (Lond.) 187: 517-551.

Fricdlander, M. J., C. S. Lin, L. R. Stanford, and S. M. Sherman (1981) Morphology of functionally identified neurons in the lateral geniculate nucleus of the cat. J. Neurophysiol. 46: 80-129.

Friedlander, M. J., L. R. Stanford, and S. M. Sherman (1982) Efrects of monocular deprivation on the structure-function relationship of individual neurons in the cat's lateral geniculate nucleus. J. Neurosci. 2: 321-330.

Fukuda, Y., C. F. Hsiao, M. Watanabe, and H. Ito (1984) Morphological correlates of physiologically identified $\mathrm{Y}-, \mathrm{X}-$, and $\mathrm{W}-$, cells in cat retina. J. Neurophysiol. 52: 999-1013.

Garraghty, P. E., M. Sur, and S. M. Sherman (1986) The role of competitive interactions in the postnatal development of $\mathrm{X}$ and $\mathrm{Y}$ retinogeniculate axons. J. Comp. Neurol. 251: 216-239.

Geisert, E. E., P. Spear, S. Zetlan, and A. Langsetmo (1982) Return of $Y$-cells in the lateral geniculate nucleus of monocularly deprived cats. J. Neurosci. 2: 577-588.

Graybiel, A. M., and C. W. Ragsdale (1982) Pseudocholinesterase staining in the primary visual pathway of the macaque monkey. Nature 299: 439-442.

Grouse, L. D., B. K. Schrier, and P. G. Nelson (1979) Effect of visual experience on gene expression during the development of stimulus specificity in cat brain. Exp. Neurol. 64: 354-364.

Guillery, R. W. (1966) A study of Golgi preparations from the dorsal lateral geniculate nucleus of the adult cat. J. Comp. Neurol. 128: 2150 .
Guillery, R. W., and D. J. Stelzner (1970) The differential effects of unilateral lid closure upon the monocular and binocular segments of the dorsal lateral geniculate nucleus in the cat. J. Comp. Neurol. 139: 413-422.

Harvey, A. R. (1980) The afferent connexions and laminar distribution of cells in area 18 of the cat. J. Physiol. (Lond.) 302: 483-505.

Hendry, S. H. C., S. Hockfield, E. G. Jones, and R. McKay (1984) Monoclonal antibody that identifies subsets of neurons in the central visual system of monkey and cat. Nature 307: 267-269.

Hockfield, S., and R. McKay (1983) A surface antigen expressed by a subset of neurons in the vertebrate central nervous system. Proc. Natl. Acad. Sci. USA 80: 5758-5761.

Hockfield, S., R. D. G. McKay, S. J. C. Hendry, and E. G. Jones (1983) A surface antigen that identifies ocular dominance columns in the visual cortex and laminar features of the lateral geniculate nucleus. Cold Spring Harbor Symp. Quant. Biol. 48: 877-889.

Hockfield, S., M. Sur, D. O. Frost, and R. McKay (1985) The expression of a $Y$-cell antigen is developmentally regulated in cat lateral geniculate nucleus. Invest. Opthal. Vis. Sci. Suppl. 26: 287.

Hoffman, K.-P., and M. Cynader (1977) Functional aspects of plasticity in the visual system of adult cats after early monocular deprivation. Phil. Trans. R. Soc. Lond. [Biol.] 278: 41 1-424.

Hoffman, K. P., J. Stone, and S. M. Sherman (1972) Relay of receptivefield properties in dorsal lateral geniculate nucleus of the cat. J. Neurophysiol. 35: 518-531.

Humphrey, A. L., M. Sur, D. J. Uhlrich, and S. M. Sherman (1985) Termination patterns of individual $\mathrm{X}$ - and $\mathrm{Y}$-cell axons in the visual cortex of the cat: Projections to area 18, to the 17-18 border regions, and to both areas 17 and 18. J. Comp. Neurol. 233: 190-212.

Kalil, R. (1978) Development of the dorsal lateral geniculate nucleus in the cat. J. Comp. Neurol. 182: 265-292.

Kratz, K. E. (1982) Spatial and temporal sensitivity of lateral geniculate cells in dark-reared cats. Brain Res. 251: 55-63.

Kratz, K. F., S. V. Webb, and S. M. Sherman (1978a) Studies of the cat's medial interlaminar nucleus: A subdivision of the dorsal lateral geniculate nucleus. J. Comp. Neurol. 181: 601-614.

Kratz, K. E., S. V. Webb, and S. M. Sherman (1978b) Effects of early monocular lid suture upon neurons in the cat's medial interlaminar nucleus. J. Comp. Neurol. 181: 615-626.

Kralz, K. E., S. M. Sherman, and R. Kalil (1979) Lateral geniculate nucleus in dark-reared cats: Loss of $Y$ cells without changes in cell size. Science 203: 1353-1355.

Lennie, P. (1980) Parallel visual pathways. Vision Res. 20: 561-594.

MacAvoy, M. G., S. Hockfield, and M. Sur (1985) Development of antigen expression in a possible $Y$-cell pathway through the cat lateral geniculate nucleus and visual cortex. Soc. Neurosci. Abstr. 11: 224.

MacAvoy, M. G., S. Hockfield, and M. Sur (1986) Further evidence for a specific antigen that distinguishes $\mathrm{Y}$-cells in the cat lateral geniculate nucleus. J. Neurosci. Abstr. 12: 439.

Mangel, S. C., J. R. Wilson, and S. M. Sherman (1983) Development of neuronal response properties in the cat dorsal lateral geniculate nucleus during monocular deprivation. J. Neurophysiol. 50:240-262.

McKay, R. D. G., and S. Hockfield (1982) Monoclonal antibodies distinguish antigenically discrete neuronal types in the vertebrate central nervous system. Proc. Natl. Acad. Sci. USA 79: 6747-6751.

Movshon, J. A., and R. C. Van Sluyters (1981) Visual neural development. Annu. Rev. Psychol. 32: 477-522.

Mower, G. D., J. L. Burchfiel, and F. H. Duffy (1981) The effects of dark-rearing on the development and plasticity of the lateral geniculate nucleus. Dev. Brain Res. 1: 418-424.

Mower, G. D., W. F. White, and F. H. Duffy (1985) GABA receptor binding in normal and monocularly deprived cats. Invest. Ophthal. Vis. Sci. Suppl. 26: 9.

Raczkowski, D., and A. C. Rosenquist (1980) Connections of the parvocellular $C$ laminae of the dorsal lateral geniculate nucleus with the visual cortex in the cat. Brain Res. 199: 447-451.

Rodieck, R. W. (1979) Visual pathways. Annu. Rev. Neurosci. 2: 193 225.

Saito, H. A. (1983) Morphology of physiologically identified X-, Yand W-type retinal ganglion cells of the cat. J. Comp. Neurol. 221. $279-288$.

Sanderson, K. J. (1971) The projections of the visual field to the lateral geniculate and medial interlaminar nuclei in the cat. J. Comp. Neurol. 143: 101-118.

Sherman, S. M., and P. D. Spear (1982) Organization of visual path- 
ways in normal and visually deprived cats. Physiol. Rev. 62: 738855.

Sherman, S. M., K. P. Hoffman, and J. Stone (1972) Loss of a specific cell type from the dorsal lateral geniculate nucleus in visually deprived cats. J. Neurophysiol. 35: 552-541.

Stanford, L. R., M. J. Fricdlander, and S. M. Sherman (1983) Morphological and physiological properties of geniculate $\mathrm{W}$-cells of the cat: A comparison with X-and Y-cells. J. Neurophysiol. 50: 582608.

Stanford, L. R., and S. M. Sherman (1984) Structure/function relationships of retinal ganglion cells in the cat. Brain Res. 297: 381-386.

Stone, J., and B. Dreher (1973) Projection of X-and $Y$-cells of the cat's lateral geniculate nucleus to areas 17 and 18 of visual cortex. J. Neurophysiol. 36: 551-567.

Sur, M., A. L. Humphrey, and S. M. Sherman (1982) Monocular deprivation affects $\mathrm{X}$ - and $\mathrm{Y}$-cell retinogeniculate terminations in cats. Nature 300:183-185.

Sur, M., S. Hockfield, M. MacAvoy, P. Garraghty, M. Kritzer, and R.
McKay (1984) A monoclonal antibody that may identify Y-cells in the cat lateral geniculate nucleus. Soc. Neurosci. Abstr. 10:297.

Weller, R. F., and A. I. Humphrey (1985) Structural correlates of functional subgroups among X-cells in the cat LGN. Soc. Neurosci. Abstr. 11: 318 .

Wiesel, T. N., and D. H. Hubel (1963) Effects of visual deprivation on morphology and physiology of cells in the cat's lateral geniculate body. J. Neurophysiol. 26: 978-993.

Wong-Riley, M. T. (1979) Changes in the visual system of monocularly sutured or enucleated cats demonstrated with cytochrome oxidase histochemistry. Brain Res. 171: 11-28.

Wong-Riley, M. T., and E. Carroll (1984) Effect of impulse blockage on cytochrome oxidase activity in monkey visual system. Nature 307 : 262-264.

Wong-Riley, M. T., and D. A. Riley (1983) The effect of impulse blockage on cytochrome oxidase activity in the cat visual system. Brain Res. 261:185-193. 